\title{
Exploring All I See: Interdisciplinary Affinity and Goal Orientations of Physics and Engineering Majors
}

\author{
Tyler D. Scott ${ }^{1}$ and Riley Harder ${ }^{2}$ \\ ${ }^{1}$ Department of Physics, Northwestern College, 101 7th Street SW, Orange City, IA 51041 \\ ${ }^{2}$ Department of Psychology, Northwestern College, 101 7th Street SW, Orange City, IA 51041
}

\begin{abstract}
Previous work has suggested that a mastery goal orientation is very strongly and significantly correlated with interdisciplinary affinity. Also, students attracted to different fields differ in their interdisciplinarity and motivations. This work seeks to establish and understand the quantitative connection between mastery orientation and interdisciplinary affinity and identify ways in which physics and engineering students are different in these characteristics. This is accomplished through surveys and interviews with physics and engineering undergraduates at liberal arts colleges. Results confirm the strong link between mastery orientation and interdisciplinary affinity. They also show that mastery orientation and interdisciplinary affinity are connected to similar motivations. This has important implications for physics educators who see both physics and engineering students in their classrooms.
\end{abstract}

Keywords: Interdisciplinarity, Goal Orientation, Motivation

\section{INTRODUCTION}

STEM fields are increasingly in need of researchers with interdisciplinary perspectives [1]. Physics in particular includes many highly interdisciplinary fields such as biophysics, chemical physics, and geospace science. However, physics research has a silo problem in that physics fields have high rates of selfcitation and low rates of cross-disciplinary citation [2-4].

Little work has been done to understand the interdisciplinarity of physics students. Previous work has found that high physics identity was significantly related to interdisciplinary affinity $[5,6]$. Preliminary results showed that a measure of mastery orientation was significantly related to higher interdisciplinary affinity. There was also an intriguing difference between physics and math; physics identity was a stronger and more robust predictor of interdisciplinary affinity than was math identity.

Another comparison of interest to physics educators is to engineering students. Many of the students in introductory, calculus-based physics courses are engineers. At small colleges that offer engineering, the departments are often housed together. Engineers are also expected to be interdisciplinary, they often share introductory courses with physicists, and those outside the fields generally lump the engineers and physicists together.

The goal of this work is to identify and begin to understand some of the differences between undergraduate physics and engineering students. To that effect, we were guided by these research questions:

RQ1. How do physics and engineering majors differ in their interdisciplinary affinity and goal orientations?

RQ2. To what extent can students' goal orientations and other motivations explain differences in interdisciplinary affinity?

Interdisciplinary Affinity (IA) is defined as students interest and desire to integrate information and perspectives from multiple disciplines as well as self-perceptions of their competence to do so [6]. This framework emphasizes the affective domain rather than performance measures.
The goal orientation literature includes many points of view. Researchers describe several orientations and disagree on the extent to which they are fixed or malleable by situation [7]. For this work, we used mastery, performance, and workavoidance orientations. A student has a mastery (or task) orientation when carrying out a task (such as studying or problem solving) for the sake of personal improvement or understanding. The student with a performance orientation is concerned with getting good grades or proving ability to others. A work avoid (or performance avoid) orientation is evidenced by a preference to avoid tasks that might show lack of ability. It is important to note here that these goal orientations are not mutually exclusive. Students can exhibit both mastery and performance orientations, and it can be argued that having both is beneficial [8].

\section{METHODS}

The first component of the study was an online survey sent to physics and engineering majors at six Midwestern, liberal arts colleges. Students were offered a chance at winning a gift card in exchange for their participation.

Students from all six colleges and from all four years responded. The responses totaled 97 , with 48 physics and 47 engineering majors. Of these, 22 were women; 6 women were engineering majors (13\% of all engineers) and the other 16 were physics majors (33\% of all physicists). The respondents included 25 freshmen, 24 sophomores, 30 juniors, and 18 seniors. The population was primarily white at $95 \%$. While all six schools offer a physics major, most of the engineering majors came from the one school which has an ABET accredited, general engineering program.

The survey included items to to measure IA, goal orientations, career interests, and demographic information. IA was measured by responses to these four items: "People in my field of study could learn a lot from other fields", "I hope to gain general knowledge across multiple fields", "I identify relationships between topics from different courses", and "Talking with people who have different interests than me is fas- 
cinating" [6]. Goal orientations were measured using items from Faber et al. [9] who drew from Shell and Husman [10]. While many goal orientation instruments have been published, this was chosen because it has been used successfully in studies of engineering students. For all these items, students were asked their agreement from "strongly disagree" to "strongly agree" on an anchored, five-point scale.

The qualitative portion of the study focuses on interviews with three students chosen for their responses to the IA and goal orientation survey items. John ${ }^{1}$ is a physics major with both high interdisciplinary affinity and mastery orientation. Lysander and Rufus are engineering majors. Lysander displayed low IA and mastery orientation on his survey, while Rufus showed high IA and mastery orientation.

The students were interviewed using a semi-structured interview protocol for 35-50 minutes. Questions probed the students' answers to the IA and goal orientation questions, career goals and interests, and physics and engineering identities.

Qualitative data analysis followed a directed content approach [11]; analysis began with predefined codes but allowed for emerging codes should they appear. Predefined codes pertaining to interdisciplinary affinity focused on interest, perceived ability, and critical awareness. Generally, critical awareness is an "awareness that 'truth' and 'knowledge' in any discipline are susceptible to influences by social factors" [12]. In this context, it is a recognition that one's discipline has a traditional way of thinking about problems and that insight from other disciplines should also be considered. Goal orientation codes consisted of mastery, performance, and work avoidance.

\section{RESULTS AND DISCUSSION}

\section{Quantitative}

The quantitative data show some interesting differences between the physics and engineering majors. A Welch's ttest comparing the interdisciplinary affinity of physics $(M=$ $4.26, S D=0.48)$ and engineering $(M=3.97, S D=0.68)$ majors shows a significant difference between the populations $(t(89)=2.5, p<0.05)$. A comparison of goal orientations also reveals a significant difference; physics majors $(M=4.65, S D=0.47)$ had higher mastery orientation $(t(88)=2.4, p<0.05)$ than engineering majors $(M=4.39, S D=0.63)$. No significant difference was found in performance orientation or work avoidance.

We hypothesized mastery orientation would be connected to interdisciplinary affinity [13], so we built a linear model with the latter as the outcome. Predictors included in the model were year in school, gender, the various goal orientations, and being a physics major. The results are shown in Table I. Only mastery orientation $(\beta=0.71, p<0.001)$

\footnotetext{
${ }^{1}$ All names used are pseudonyms.
}

TABLE I. Regression model predicting interdisciplinary affinity. $* * *$ : $\mathrm{p}<0.001 ;$ ns: not significant.

\begin{tabular}{lcc} 
Parameter & $\beta$ & Sig. \\
\hline Intercept & & $* * *$ \\
\hline Gender (1= Male, 2 = Female) & -0.03 & $\mathrm{~ns}$ \\
Year in School $^{\dagger}$ & & \\
$\quad$ 2nd year & 0.46 & $\mathrm{~ns}$ \\
$\quad$ 3rd year & 0.10 & $\mathrm{~ns}$ \\
$\quad$ 4thd year & 0.25 & $\mathrm{~ns}$ \\
Mastery Orientation & 0.71 & $* * *$ \\
Performance Orientation & 0.02 & $\mathrm{~ns}$ \\
Work Avoidance & 0.02 & $\mathrm{~ns}$ \\
Physics Major & 0.37 & $\mathrm{~ns}$ \\
\hline Adusted $R^{2}$ &
\end{tabular}

Adjusted $R^{2}=0.20$

$F(8,88)=3.99, p<0.001$

${ }^{\dagger}$ Reference level is first year.

was a significant predictor, leading to the conclusion that mastery orientation has a more important connection to interdisciplinary affinity than students' majors has.

\section{Qualitative}

Since the quantitative data and results only speak to correlation, we looked at the student interviews for deeper insight into the connection between interdisciplinary affinity and goal orientation.

A significant outcome from the qualitative analysis was the importance of levels of motivation. As we looked for the connections between goal orientation and IA, what emerged were motivational levels above goal orientation. Here the Motivated Action Theory (MAT) [7] was useful in understanding the importance of multiple levels of motivation. Goal orientations (called "Achievement Goals" in MAT) are situated in a hierarchy of motivations. At the highest level are "Self Goals," which are, "fundamental outcomes that all individuals must achieve, to some extent, to lead normal, healthy, fulfilling lives." Examples include Agency, Affiliation, and Esteem. Below self goals but above achievement goals lie "Principle Goals" that are general guidelines that might be useful for attaining self goals. Examples provided by DeShon and Gillespie [7] are growth, fairness, structure, and social value. In this view, goal orientations of mastery and performance reflect the behaviors employed to pursue higher goals. An important result of MAT confirmed by our study is that students can have similar goal orientations which are in service of different principle and, ultimately, self goals.

\section{Lysander}

Interview data show Lysander only valued interdisciplinarity within STEM fields.

"I think [making connections across courses] is important more in your area of study. Engineering, it'd be good to know physics and chemistry. 
I don't know if it's necessarily as important to know literature and stuff. ... I think it's a lot less important that I take a literature class or an art class. Well-rounded, I think is good in more your area of study."

Lysander's interdisciplinary affinity was motivated by his future career. When asked why it was important to be wellrounded, he answered by describing how useful it would be for him as a professional engineer.

“Okay, say I'm gonna be a mechanical engineer; I still need to know some structural knowledge of how do bridges work. How do buildings stand? I need to know some chemistry, even if I'm not gonna be necessarily using chemistry when I'm designing a transmission. I still have to know at least something about that."

Interestingly, Lysander displayed primarily a mastery goal orientation in his interview. For example, he used classic mastery orientation language when asked about what makes him satisfied with a class he takes.

"I think part [of feeling satisfied] would probably be the feeling that I accomplished something, so that I learned the material well, and that I had a better understanding now because I had taken this course."

This contrasted with his survey results which showed low mastery orientation. A possible explanation would be social desirability pressure that the interviewers inadvertently applied.

But either way, the data still show the important connection between goal orientation and the higher levels of motivation in MAT. To Lysander, his mastery orientation was, "because I want to get better so I could be as good of an engineer as I can." The pattern that emerged with Lysander is that his mastery orientation and IA are both connected to the same motivation, success in his future engineering career.

\section{Rufus}

In his interview, Rufus described an interdisciplinary affinity that transcended STEM boundaries. Connections to his engineering education that he saw included economics, philosophy, history, psychology, human health, politics, and theology. In contrast to Lysander, he recognized the importance of the arts and humanities to his education. But he did share Lysander's motivation for interdisciplinarity. Even though his IA was broad, it also was motivated by his career.

"Being well rounded is pretty important for every major including engineering because ... you need a context as to where you're working in and how you're doing things there. ... So, being well rounded in psychology, philosophy, you can understand the history, how people think in that city, in whatever context you're in.
Rufus also had high mastery orientation. Like Lysander, he used classic mastery orientation descriptors when asked about what gives him satisfaction when taking a class.

"Being satisfied means that the amount of work and effort that I put into the class, if I studied a lot for an exam and got a B-, I'd be satisfied with that because I studied my hardest, whereas if I didn't study and I got a C+, I wouldn't be as satisfied because I knew that I could have studied more for that. So, being satisfied, I think, is knowing that I've done the best that I could."

And, like Lysander, Rufus' mastery orientation was motivated by his future career in engineering.

"I think being challenged helps you to learn and to grow even more to do better in your field."

He also discussed his rejection of a performance goal orientation by arguing that a performance orientation hurts workplace success.

"If you're a 4.0 GPA student and all you do is work hard to do better than others and to get a good grade... Even though you're super smart and super brilliant... not a lot of people are going to want to work with you... I don't define myself by my grades. I don't care how good or bad I do. I don't care how I compare to other students. I don't define myself by who is smarter than me, who is not smarter than me."

To summarize, Rufus, like Lysander, related his mastery orientation and IA to the same motivation, his engineering career.

John

On the other hand, John connected neither mastery orientation nor IA to his career. However, though neither was connected to career, they were still connected at the same Self Goal level of MAT.

John displayed a broad interdisciplinary affinity that transcended STEM boundaries. He discussed connections between his physics interests and religion, ethics, philosophy, communications, psychology, and literature. Though he was accepted at a public, R1 university's physics program, he chose to attend a small liberal arts college because of its interdisciplinary honors program.

"I'm looking for more than just answers to my science questions. ...I'm trying to explore all of what I see in the world. ... It isn't just about a physics answer. Perhaps it's about a religious or an ethical answer, things like that. Certainly, those things tie into what you see in physics."

But while John had similar IA to Rufus, his motivation behind it was different. While Lysander and Rufus saw interdisciplinarity as a means to being a better engineer, John saw it as personal fulfillment. 
'Life isn't about just being a scientist. It's important to be very knowledgeable in your field, but it's important to be a person, too. I think that if you're going to be the best person you can be, that you should also understand fields of psychology or philosophy or literature. All of those things, I think, are important to making a good person, so to speak."

John also exhibited a strong mastery orientation. His approach is probably best summarized by his problem solving motivation.

"I wouldn't solve a problem because it would make me well-known and get me a Nobel Prize. I would solve a problem because I thought it needed solving."

While Lysander and Rufus connected their goal orientations to their engineering futures, John's mastery orientation was motivated by interest and fascination.

"This is what I want to do, because it made me happy. It felt good. Knowing more than I previously did about these topics. I like this stuff. I don't just want to be a physics major because I hear they make good money at doing this or that. I'm a physics major because I want to know more about these things because it's incredibly fascinating to me."

For John, both interdisciplinary affinity and mastery orientation were motivated by a sense of personal fulfillment.

\section{DISCUSSION, CONCLUSIONS, AND FUTURE WORK}

The quantitative data show differences between physics and engineering majors in both interdisciplinary affinity and mastery orientation. More analysis indicates that when mastery orientation is considered, the physics major is no longer significantly related to interdisciplinary affinity. The key relationship is between mastery orientation and IA.

Limitations to this part of the study are primarily sample related. Ideally this work should be replicated on a larger scale and with a more representative physics and engineering student population by including larger colleges, research universities, and schools serving more diverse students.

The qualitative results provide a more detailed look at the IA and goal orientations of the students. While an explicit connection between mastery orientation and IA was not clear, both are connected to the same higher motivations. Both Lysander and Rufus' IA and mastery orientations were connected to their future engineering careers. In the context of MAT, it would appear that they are connected at the "Principle Goals" level. In John's case, his mastery orientation and IA were both connected to his sense of fulfillment as a person, the "Self Goals" level of MAT. While they were different for the engineers and physicist, in all three cases mastery orientation and IA were connected to the same higher motivation level. Additional work should be done to provide more insight into this connection. While they are connected to the same motivation level, this data seems to show simply a correlation. A causal explanation is still to be found.

The practical implications of this work are greatest for physics educators who have engineering majors in their classrooms. Successful strategies to motivate engineers might be different than those that work on physics majors and vice versa. Identifying the ramifications of this could be a rich area of research.

\section{ACKNOWLEDGMENTS}

The authors would like to thank the participants of our study and the engineering and physics departments of the participating colleges for their assistance. They also thank a colleague for valuable feedback on the manuscript. This work was funded by a grant from Northwestern College.
[1] National Science Foundation, Investing in America's Future: Strategic Plan 2006-2011, Tech. rep., National Science Foundation (2006).

[2] National Science Board, Science \& Engineering Indicators 1998, Tech. rep., National Science Foundation, Arlington, VA (1998).

[3] L. Ortega, and K. Antell, College \& Research Libraries 67, 446-462 (2000).

[4] T. Van Leeuwen, and R. Tijssen, Research Evaluation 9, 183187 (2000).

[5] T. D. Scott, Z. Hazari, and G. Potvin, "Interdisciplinary Thinking and Physics Identity," in Physics Education Research Conference, edited by P. V. Engelhardt, A. D. Churukian, and D. L. Jones, Portland, OR, 2013.

[6] T. D. Scott, Z. Hazari, G. Potvin, P. M. Sadler, and G. Sonnert, "Interdisciplinary Affinity: Definitions and Connections to Physics Identity," in Physics Education Research Conference, edited by P. V. Engelhardt, A. D. Churukian, and D. L. Jones, Minneapolis, MN, 2014.

[7] R. P. DeShon, and J. Z. Gillespie, Journal of Applied Psychology 90, 1096-1127 (2005).

[8] J. M. Harackiewicz, K. E. Barron, and A. J. Elliot, Educational Psychologist 33, 1-21 (1998).

[9] C. J. Faber, S. J. Grigg, A. Kirn, J. M. Chasmar, and L. Benson, 121st ASEE Annual Conference and Exposition (2014).

[10] D. F. Shell, and J. Husman, Journal of Educational Psychology 100, 443-459 (2008), ISSN 1939-2176.

[11] H.-F. Hsieh, and S. E. Shannon, Qualitative health research 15 , 1277-88 (2005).

[12] M. Borrego, and L. K. Newswander, The Review of Higher Education 34, 61-84 (2010), ISSN 1090-7009.

[13] T. D. Scott, Chasing Polys: Interdisciplinary Affinity and its Connection to Physics Identity, Dissertation, Clemson University (2014). 